\title{
APPENDIX-A BRIEF REPORT ON RESEARCH IN THE U.S.S.R.
}

\section{(By V. I. Krassovsky and G. I. Galperin)}

In the period between the last IAU meeting in $195^{8}$ and the end of 1960 , research on airglow and aurorae was carried out within the broad programme of the IGY and IGC in the U.S.S.R. Detailed results are described in $(\mathbf{r}-\mathbf{5} \mathbf{r})$. Only the most interesting results will be indicated here.

\section{Airglow emissions}

I. At various points of the U.S.S.R. detailed observations on airglow were carried out especially on hydroxyl bands which, with the aid of image tubes, were studied up to $11000 \AA$. It is shown that: $(a)$ at the Yakutsk station the hydroxyl intensity is correlated with its rotational temperature, if the latter exceeds $200-250^{\circ} \mathrm{K} ;(b)$ at the Moscow station this dependence is not observed, while the band intensities are similar to those which correspond to temperatures lower than $25^{\circ} \mathrm{K}$ at Kakutsk; $(c)$ at Abastumani hydroxyl intensity and rotational temperatures are correlated; $(d)$ in contrast to the Moscow observations seasonal intensity variations with winter maximum are observed at Yakutsk and Abastumani; $(e)$ there is a tendency for the hydroxyl rotational temperatures to increase with the rise of the latitude of observation; $(f)$ relative intensities of bands with relatively high and low $v^{\prime}$ vary significantly with place, season and rotational temperatures $\left(3,7,10,11,1_{3}, 16-29,4 r\right)$.

2. A regular registration of the narrow airglow hydrogen $\mathrm{Ha}$ line was achieved; its intensity amounts to tens of Rayleighs (3, 6, ro, 15, 24).

3. The following correlations between intensities of airglow emissions are established. Airglow intensities of $\mathrm{Ha}$, hydroxyl bands, $\mathrm{Na} 5890 \AA$ and [O I] $6300 \AA$ are correlated, with the exception of [ $\left.\mathrm{O}_{\mathrm{I}}\right] 6300 \AA$ and hydroxyl which, at high hydroxyl intensities at Yakutsk, are not correlated.

[N I] $5200 \AA$ emission is correlated with the [O I] $6300 \AA$ emission (15, 23, 24).

4. The airglow emission continuum is definitely registered in the visible part of the spectrum with the intensity amounting to several $R / \AA$. Two maxima in the red and blue regions are discovered; their relative intensities are not always constant $(3, \mathbf{I I}, 25,26,42)$.

\section{Auroral emissions}

1. With the aid of all-sky cameras and absolute electro-photometry it is established (5) that in most cases the main part of the emission energy flux of aurora does not come from bright distinct auroral forms of small angular dimensions (such as arcs, rays, draperies etc.), but is emitted by faint diffuse luminous surfaces of large areas in the sky which surround bright auroral forms.

2. A regular registration of auroral Doppler-shifted hydrogen emission was achieved at Loparskaya $(\mathbf{x}, 34,35,39,46)$. No significant variations were found in the range of $\sim 30 \AA$ in the line profile. The intensity maximum is usually shifted to the violet for $6-9 \AA$ in $\mathrm{Ha}$. The highest shift in $\mathrm{H} \alpha$ emission amounts to $\approx 40 \AA$. Hydrogen emission is usually observed on large portions of the sky and it does not show direct connection with bright auroral forms $(35,39)$; though this emission is usually observed as intense during geomagnetic disturbances, cases of its appearance in magnetically quiet conditions were registered. Doppler-shifted auroral hydrogen emission usually appears to be observable some hours before the commencement of the visible aurora. But cases were registered when the appearance of this emission did not lead to visible aurora. Simultaneous observations in the directions to the North, to the Zenith and to the South showed that usually the region of $\mathrm{Ha}$ luminosity in the sky: $(a)$ moves 
from the North to the South in the evening hours, $(b)$ in most cases its night intensity is higher to the South from Loparskaya, and $(c)$ moves back to the North in the morning hours $(\mathbf{r}, 39)$. Rapid intensity variations of auroral hydrogen emission during intervals of $5-15$ minutes were registered (49). Balmer decrement of hydrogen emission was determined (46).

3. The comparison of a large number of auroral spectra obtained in high and low latitudes reveals that atomic emissions of nitrogen and oxygen strengthen in high latitude as well as in low latitude aurorae of type $A$ while in high latitude aurorae of type $B$ molecular bands of $\mathrm{N}_{2}, \mathrm{O}_{2}^{+}$strengthen $(\mathbf{r}, 35,39)$.

4. During red high-altitude sunlit aurorae there was discovered the helium emission I0830 $\AA(\mathbf{2}, \mathbf{2 7})$. According to N. N. Shefov (28) this emission is due to fluorescence in the solar radiation of the metastable state of helium $2^{3} S$ He I formed in the auroral space.

5. Absolute electromagnetic measurements in various forms of aurora show that relative intensities of the red and green oxygen lines are dependent of their intensity. The number of the red line quanta per one quantum of a green line in ray forms changes from 0.0 r up to ro, pointing to the desactivation of state ${ }^{1} D(9)$.

6. Short-periodic variations of brightness in pulsating aurora were simultaneously registered in different light-filters. The average life times of ${ }^{1} S$ and ${ }^{1} D$ oxygen levels do not differ markedly from the theoretical ones $(5,47)$. The connection was discovered between pulsations and short-periodic fluctuations of the earth currents.

7. Careful electro-photometric measurements of polarization of auroral emissions with the help of a permanently rotating polaroid made it possible to establish slight polarization of emissions $4278 \AA \mathrm{N}_{2}^{+}(+4 \%), 486 \mathrm{r} \AA \mathrm{H} \beta+$ continuum $(+3 \%)$, anisotropy being directed along magnetic force lines. As was expected polarization of $5577 \AA$ is equal to zero.

8. During red high-altitude aurorae with the help of Fabry-Perot interferometer, an essential increase of the width of the red oxygen line $6300 \AA$ with the growth of its intensity was discovered $(4,43,44)$. The maximum observed width of this emission corresponds to temperatures up to $3500^{\circ} \mathrm{K}$. Besides that, the interferometric determinations of the widths of other auroral and airglow emissions at different latitudes, including the registration of the width of $5200 \AA[\mathrm{N} \mathrm{I}]$ and $8446 \AA\left[\mathrm{O}_{\mathrm{I}}\right]$, were made $(4,42,43,44)$.

\section{REFERENCES}

I. Galperin, G. I. Spectral, Electro-photometrical and Radar Researches of aurora and airglow, IGY series, problem IV, Acad. Sci. U.S.S.R., Moscow, No. 1, 7, 1959.

2. Mironov, A. V., Prokudina, V. S. and Shefov, N. N. Ibid., No. I, 20, I 959.

3. Shefov, N. N. Ibid., No. I, 25, 1959.

4. Mularchik, T. M. Ibid., No. I, 4I, 1959.

5. Jorjio, N. V. Ibid., No. I, 30, 1959.

6. Prokudina, V. S. Ibid., No. $1,43,1959$.

7. Shuiskaya, F. K. Ibid., No. I, 45, 1959.

8. Potapov, B. P., Rappoport, Z. and Barsuk, T. B. Ibid., Nos. 2-3, 42, 1960.

9. Jorjio, N. V. Ibid., Nos. 2-3, 45, I960.

ro. Fishkova, L. M. and Markova, G. V. Ibid., Nos. 2-3, 49, I960.

II. Shefov, N. N. Ibid., Nos. 2-3, 57, 1960 .

12. Karyagina, Z. V. Ibid., Nos. 2-3, 60, 1960.

13. Gynullina, R. Ch. and Karyagina, Z. V. Ibid., Nos. 2-3, 63, 1960.

I4. Mironov, A. V. Ibid., Nos. 2-3, 66, 1960.

15. Prokudina, V. S. Ibid., Nos. 2-3, 68, 1960.

16. Sukhoivanenko, P. I. Ibid., Nos. 2-3, 7I, 1960.

x7. Yarin, V. I. Ibid., Nos. 2-3, 72, 1960.

r8. Shefov, N. N. Ibid., No. 4, (in press). 
19. Yarin, V. I. Ibid., No. 4, (in press).

20. Shefov, N. N. Ibid., No. 4, (in press).

2r. Shefov, N. N. and Yarin, V. I. Ibid., No. 4, (in press).

22. Krassovsky, V. I. Ibid., No. 4, (in press).

23. Prokudina, V. S. Ibid., No. 4, (in press).

24. Yarin, V. I. Ibid., No. 4, (in press).

25. Yarin, V. I. Ibid., No. 4, (in press).

26. Shefov, N. N. Ibid., No. 4, (in press).

27. Fedorova, N. I. Ibid., No. 4, (in press).

28. Shefov, N. N. Ibid., No. 4, (in press).

29. Shuiskaya, F. K. Ibid., No. 4, (in press).

3o. Yarin, V. I. Ibid., No. 4, (in press).

31. Krassovsky, V. I. Priroda 5, 55, x957.

32. Krassovsky, V. I. Priroda 12, $87,1957$.

33. Karyagina, Z. V. Astr. Circ. U.S.S.R., 186, 1957.

34. Galperin, G. I. Astr. $\mathscr{F}$., Moscow. 35, 3, 382, $195^{8}$.

35. Krassovsky, V. I., and Galperin, G. I. et al. Ann. Géophys. 14, No. 3, $195^{8}$.

36. Fishkova, L. M. and Markova, G. V. Astr. Circ. U.S.S.R., No. I91, 1958.

37. Fishkova, L. M. and Markova, G. V. Astr. Circ. U.S.S.R., No. I96, 1958.

38. Fishkova, L. M. and Markova, G. V. Astr. Circ. U.S.S.R., No. 208, 14-17, 1959.

39. Galperin, G. I. $\quad$ Planet. Space Sci., I, 57-62, 1959.

40. Bolunova, A. D. and Morozov, V. M. Izvest. Acad. Nauk S.S.S.R., ser. geophys. No. 2, $321,1959$.

4r. Prokudina, V. S. Izvest. Acad. Nauk S.S.S.R., ser. geophys., No. 4, 629-631, 1959.

42. Mularchik, T. M. Izvest. Acad. Nauk S.S.S.R., ser. geophys., No. I2, 1902, 1959.

43. Mularchik, T. M. Doklady Acad. Nauk S.S.S.R. 160, 303, 1960.

44. Mularchik, T. M. Izvest. Acad. Nauk S.S.S.R., ser. geophys., No. 3, 449, 1960.

45. Shuiskaya, F. K. Izvest. Acad. Nauk S.S.S.R., ser. geophys., No. 3, I960.

46. Shuiskaya, F. K. Astr. F., Moscow 37, I, 186, 1960.

47. Jorjio, N. V. Izvest. Acad. Nauk S.S.S.R., ser. geophys., No. 5, 714, 1960.

48. Karyagina, Z. V. and Tulenkova, L. N. Izvest. Astrophys. Inst., Acad. Nauk Kaz. S.S.R. 9, 86-95, 1960.

49. Shuiskaya, F. K. and Trunov, V. G. Izvest. Acad. Nauk S.S.S.R., ser. geophys. (in press).

50. Frishman, I. G. Optika i Spectr., No. 3, 323-328, 1959.

51. Fishkova, L. M. and Markova, G. V. Bull. Abastumani astrophys. Obs., No. 24, 1959. 